\title{
Triangular temporal alopecia - two case reports, dermoscopy and review
}

\begin{abstract}
Triangular temporal alopecia, also known as congenital triangular alopecia or Brauer nevus is a benign and unusual non-scarring pattern of hair loss. Was published in the literature cited on PubMed about 130 cases and has been discussed the use of dermoscopy as an important tool for diagnosis. Usually located in the temporal region and is usually unilateral. It may be triangular, oval or lancet-shaped. Manifested commonly in childhood and may also appear in adult life. Histopathology reveals the total number of follicles preserved and most of vellus hair. In dermoscopy is seen in the injured area vellus hairs surrounded by normal scalp with the terminals hairs. Therapeutic options are scarce, surgical excision and hair transplantation showed better aesthetic results.
\end{abstract}

Keywords: dermoscopy, vellus hairs, TTA, hair transplantation, iris nevus syndrome
Volume 2 Issue I - 2018

Ticiana de Andrade Castelo Branco Diniz, Yasmin Gama Abuawad, Fabiana Oliveira da Silva, Priscila Kakizaki, Neusa Yuriko Sakai Valente

Department of Dermatology, Hospital do Servidor Público Estadual de São Paulo, Brazil

Correspondence: Yasmin Gama Abuawad, Hospital do Servidor Público Estadual de São Paulo-SP, Rua Borges Lagoa 1209, Brazil,Tel 321 I-3 I34, Email yasmin_gama@yahoo.com.br

Received: May 16, 2017 | Published: February 05, 2018

\section{Introduction}

Triangular temporal alopecia (TTA) also known as congenital triangular alopecia or Brauer nevus was first described in 1905 by Sabouraud. ${ }^{1}$ It is characterized by a non-scarring and non-inflammatory hair loss pattern, usually located in the temporal region and varying shape may be triangular, oval or lancet. Diagnosis is clinical. ${ }^{2}$

\section{Case reports}

\section{Case report I}

A 47-years-old man presented a localized hair loss in the left temporal region since birth. On dermatological examination was observed triangular alopecia area, well defined, measuring $4 \times 3 \mathrm{~cm}$ (Figure 1) without skin changes, such as atrophy, peeling or inflammation. Dermoscopy (DermLite DL3N;3Gen) reveled in the injured area vellus hairs, surrounded by normal scalp with terminals hairs (Figure 2). No yellow spots, exclamation mark hairs or cadaver hairs were detected. He denied similar cases in the family.

\section{Case report 2}

A 48-years-old male presented a localized hair loss in the right temporoparietal region perceived since she was twelve. On dermatological examination was observed an oval area of alopecia, well-defined, measuring $1 \times 1.5 \mathrm{~cm}$ (Figure 3 ) without skin changes, such as atrophy, peeling or inflammation. Dermoscopy (DermLite DL3N; 3Gen) reveled in the injured area vellus hairs surrounded by normal scalp with terminals hairs (Figure 4). No yellow spots, exclamation mark hairs or cadaver hairs were detected. He denied similar cases in the family.

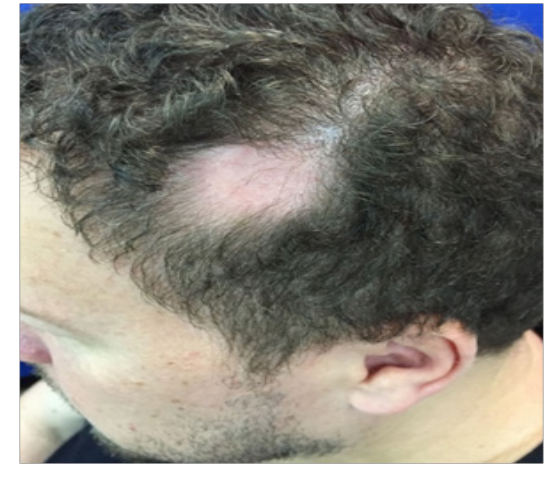

Figure I Well circumscribed triangular alopecia area $4 \times 3 \mathrm{~cm}$. No cutaneous alterations such as atrophy, scalling or inflammation.

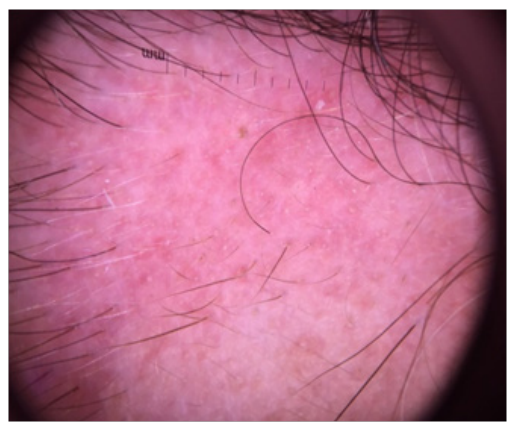

Figure 2 Alopecia area with vellus hairs surrounded by normal scalp with terminal hairs. 


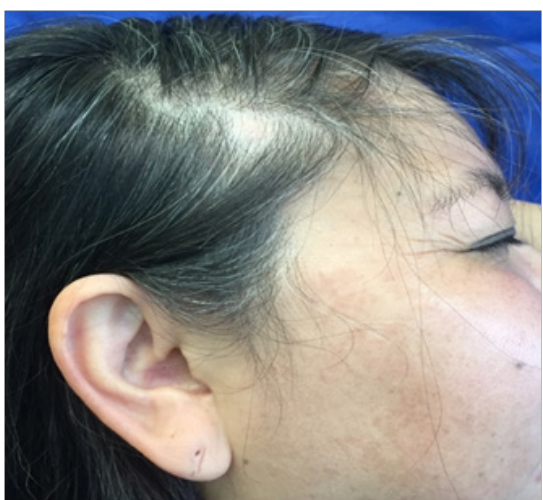

Figure 3 Oval alopecia area $I X \mid .5 \mathrm{~cm}$. No cutaneous alterations such as atrophy, scalling or inflammation.

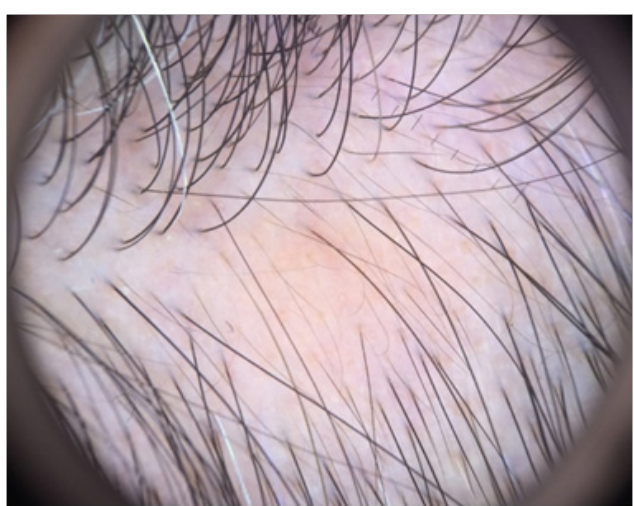

Figure 4 Dermoscopy: vellus hairs surrounded by normal scalp with termina hairs.

\section{Discussion}

The TTA is part of the group of non-scarring alopecia. Unlike the name it was given, most of the cases is not congenital, manifesting from two to nine years old, but may appear during adulthood. ${ }^{2}$ Remains stable throughout life, is usually unilateral, but about twenty percent are bilateral. ${ }^{3}$ Often affects the temporal region, but may be located in the temporoparietal region and occipital. ${ }^{4}$ Some congenital disorders were associated, such as iris nevus syndrome, phacomatosis pigmentovascularis, congenital heart disease, bone and tooth abnormalities, mental retardation and congenital aplasia cutis. ${ }^{2}$

Histopathology reveals preserved total number of follicles, but most formed by vellus hairs, some intermediaries and lack of terminals. There were no changes in the epidermis and derme. ${ }^{2}$ The proportional increase of vellus and intermediate hairs in relation to the terminals support the notion that TTA is a form of hamartoma with local follicular morphogenesis alteration.

Dermoscopy has been an important diagnostic tool, avoiding invasive procedures. TTA most common findings are white hairs, diversity of diameter and normal follicular orifice with vellus hairs surrounded by terminal hairs without atrophy or inflammation. ${ }^{5}$ It is important to rule out other conditions that preserve vellus hair. Alopecia areata is distinguished by the presence of yellow dots, black dots, exclamation mark hairs, cadaver hairs and dystrophic hairs (Table 1). Trichotillomania shows black dots and traction alopecia is observed the presence of hair casts and cadaverized hairs. ${ }^{6-8}$
Table I Comparison between TTA and AA

\begin{tabular}{|c|c|c|}
\hline & TTA & $\mathbf{A A}$ \\
\hline Onset & $\begin{array}{l}\text { Congenital or during } \\
\text { childhood or adulthood }\end{array}$ & $\begin{array}{l}\text { Childhood or } \\
\text { adulthood }\end{array}$ \\
\hline Location & $\begin{array}{l}\text { Temporal, tempoparietal } \\
\text { or occipital }\end{array}$ & No site predilection \\
\hline Dermoscopy & $\begin{array}{l}\text { Normal follicular orifice } \\
\text { with thin vellus hairs, } \\
\text { surrounded by terminal } \\
\text { hairs at the periphery } \\
\text { without atrophy or } \\
\text { inflammation }\end{array}$ & $\begin{array}{l}\text { Yellow dots, black } \\
\text { dots, exclamation } \\
\text { mark hairs, cadaver } \\
\text { hairs and dystrophic } \\
\text { hairs }\end{array}$ \\
\hline Histopathology & $\begin{array}{l}\text { Non inflammatory; } \\
\text { Preserved total number of } \\
\text { follicles, mostly formed } \\
\text { by vellus hairs, some } \\
\text { intermediaries and lack of } \\
\text { terminals }\end{array}$ & $\begin{array}{l}\text { Peribulbar } \\
\text { lymphocytic } \\
\text { inflammation, a } \\
\text { shift to catagen and } \\
\text { telogen follicles and } \\
\text { miniaturization }\end{array}$ \\
\hline
\end{tabular}

In 2011, was proposed a classification for the diagnosis of TTA that includes four main features: (I) Triangular or spear-shaped alopecia surrounding the frontotemporal region of the scalp; (II) A normal follicle orifice with vellus hairs surrounded by the terminals (using a dermoscopy); (III) Absence of fractured or exclamation mark hairs, black or yellow dots and absence of a follicular orifice (using a dermoscopy); and (IV) Lack of hair growth 6 months after the confirmation of the presence of vellus hairs, both clinically and dermoscopically. ${ }^{7}$ Therapeutic options are scarce. One case has been reported in the literature of therapeutic success after using topical minoxidil. ${ }^{9}$ The treatment of choice is surgery. Depending on the size of the affected area can be attempted excision or, if more extensive, hair transplantation..$^{10}$ Our patients have chosen not to treat.

\section{Conclusion}

Many authors believe that TTA is not an uncommon disorder but that it is under diagnosed due to diagnostic confusion with other types of non-scarring alopecia. It is important to know this diagnosis when facing a patient with non-scarring alopecia and avoid unnecessary treatments.

\section{Acknowledgements}

None.

\section{Conflicts of interest}

The authors declared that there are no conflicts of interest.

\section{References}

1. Sabouraud R. A manual of regional topographical dermatology. France: Masson; 1905. 197 p.

2. Yamazaki M, Irisawa R, Tsuboi R. Temporal triangular alopecia and review of 52 past cases. J Dermatol. 2010;37(4):360-362.

3. Trakimas C, Sperling LC, Skelton HG, et al. Clinical and histologic findings in temporal triangular alopecia. J Am Acad Dermatol. 1994;31(2 Pt 1):205-209.

4. Li VCY, Yesudin PD. Congenital triangular alopecia. Int J Trichology. 2015;(2):42-53. 
5. Fernández-Crehuet $\mathrm{P}$, Vaño-Galván $\mathrm{S}$, Martorell-Calatayud $\mathrm{A}$, et al. Clinical and trichoscopic characteristics of temporal triangular alopecia: A multicenter study. J Am Acad Dermatol. 2016;75(3):634-637.

6. Karadağ Köse Ö, Güleç AT. Temporal triangular alopecia: significance of trichoscopy in differental diagnosis. J Eur Acad Dermatol Venereol. 2015;29(8):1621-1625.

7. Inui S, Nakajima T, Itami S. Temporal triangular alopecia: Trichoscopy diagnosis. Journal of Dermatology. 2011;39(6):572-574.

8. Strazzulla LC, Wang EHC, Avila L, et al. Alopecia areata. Disease characteristics, clinical evaluation, and new perspectives on pathogenesis. J Am Acad Dermatol. 2018;78(1):1-12.
9. Bang CY, Byun JW, Kang MJ, et al. Successful treatment of temporal triangular alopecia with topical minoxidil. Ann Dermatol. 2013;25(3):387388 .

10. Chung J, Sim JH, Gye J, et al. Successful hair transplantation of treatment of acquired temporal triangular alopecia. Dermatol Surg. 2012;38(8):14041406. 